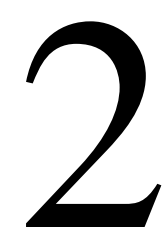

\title{
INCLUSIÓN EDUCATIVA Y DIVERSIDAD CULTURAL EN AMÉRICA LATINA
}

Inclusive Education and Cultural Diversity in Latin America

Néstor López*

\section{$\underline{\text { RESUMEN }}$}

El artículo centra su atención en los desafíos que enfrentan las políticas de equidad educativa en América Latina, región signada por una gran diversidad cultural. Tras detenerse en aportar algunas precisiones en torno a las nociones de equidad y diversidad, el texto pasa a una breve caracterización de la heterogeneidad social y cultural en los países latinoamericanos para centrarse luego en identificar un conjunto de factores y dinámicas propias del funcionamiento del sistema educativo -en particular en el nivel medio de enseñanza- que hacen obstáculo a la meta de una educación para todos.

PALABRAS ClAVE: Equidad Educativa, Diversidad Cultural, Escuela Media, América Latina.

\section{ABSTRACT}

The paper focuses on the challenges which educational equity policies are faced with in Latin America -a region characterized by its great cultural diversity. After discussing equity and diversity conceptualizations and debates, the paper gives a brief overview of social and cultural heterogeneity in Latin American. The paper then identifies

\footnotetext{
* Instituto Internacional de Planetamiento Educativo (IIPE) UNESCO Buenos Aires (Argentina).
} 
factors and dynamics of the educational system -in particular teaching at secondary school level, which represent an obstacle to the goal of education for all.

KEY WORDS: Inclusive Education, Cultural Diversity, Middle School, Latin America.

$* * * * *$

\section{INTRODUCCIÓN}

Hay una pregunta que es central en el debate sobre las políticas educativas en América Latina: ¿Cómo hacer que esas políticas sean equitativas en países signados por su gran diversidad cultural e identitaria? Para poder responder a esa pregunta es necesario poner el foco en dos conceptos que están presentes en ella: Equidad y diversidad. Ambas aparecen como conceptos centrales en ese debate.

Ahora bien, cada una de esas categorías está asociada a otra que la estructura, y que la completa en su sentido. No es posible hablar de equidad sin hacer referencia a la idea de igualdad. Como se verá a lo largo de este texto, equidad e igualdad son dos conceptos que se necesitan mutuamente. De modo similar, la noción de diversidad quedaría muy limitada si uno quisiera abordarla prescindiendo de la tensión que tiene con la idea de desigualdad.

En este artículo buscaré hacer un aporte en la búsqueda de respuestas a esa pregunta inicial, centrando el análisis en un campo de análisis que podría definirse como "equidad educativa y diversidad cultural". Lo haré aceptando estas dos premisas como punto de partida: no se puede hablar de equidad sin hablar de igualdad, y no se puede abordar el tema de la diversidad prescindiendo de la desigualdad. Igualdad y desigualdad, paradójicamente, son dos conceptos que piden estar presentes en este trabajo, aunque no se los convoque.

Todo debate sobre las políticas -y en particular cuando éstas se referencian a territorios específicos (por ejemplo, políticas en América Latina)- remite simultáneamente a dos planos en la reflexión. Uno más analítico, conceptual, donde uno busca poner en juego categorías que aparecen como productivas. El otro, atento a lo que provee la empiria, que nos habla de ese territorio. Este artículo se mueve en esos dos registros, desarrollando inicialmente algunas categorías de análisis que serán luego utilizadas para reflexionar sobre la situación educativa de la región. En este caso, se pone el énfasis en la escuela media, por ser allí donde más se hace visible la dificultad por abordar el desafío de garantizar una educación de calidad en un contexto de gran diversidad. Este texto, elaborado en un tono más cercano al ensayo o la reflexión, se inscribe en la expectativa de generar un aporte en el debate actual sobre las políticas de equidad educativa en América Latina. 


\section{EQUIDAD E IGUALDAD}

El punto de partida será, entonces, explicitar algunas categorías básicas. En principio, cuál es la noción de equidad sobre la que se sustenta este texto, y luego, de qué se está hablando cuando se hace referencia a equidad educativa.

\section{$\underline{\text { 2.1 La noción de equidad }}$}

La relación entre equidad e igualdad suele ser poco clara. En muchos casos suele ser usada como sinónimos, y aparecen mencionadas indistintamente. En otros, en cambio, aparecen como términos casi opuestos, en particular en el campo de las ideas políticas. La noción de equidad tuvo un gran impulso en el campo de las políticas públicas durante las reformas del Estado orientadas a promover la centralidad del mercado como eje de la dinámica social, y en consecuencia se la asocia con el pensamiento neoliberal, en tanto la idea de igualdad es vista como más "progresista".

Diferentes autores, sin embargo, nos ofrecen herramientas conceptuales desde donde poder identificar la especificidad de cada uno de esos términos, así como la relación que se establece entre ambos. Amartya Sen señala que toda teoría normativa del orden social que haya resistido el paso del tiempo se basa en un principio de igualdad. En algunos casos se busca igualdad en el ejercicio de las libertades, en otros igualdad en el acceso a bienes elementales, igualdad de recursos o de derechos, pero en todos los casos hay como factor común la búsqueda de una igualdad como horizonte. Es decir, lo que diferencia una corriente de pensamiento de las otras no es el promover o no la igualdad, sino cuál es el tipo de igualdad que promueven (SEN, 1995).

El autor destaca que este debate sobre cuál igualdad promover como horizonte de una política es inevitable. No es posible pretender la coexistencia de igualdades múltiples en diferentes dimensiones de la vida por el hecho de que cada uno de nosotros somos, precisamente, desiguales a los otros. Si todos fuéramos exactamente iguales, la igualdad en una de las dimensiones de la vida se traduciría en igualdad en todas las restantes, pero es la desigualdad entre los sujetos lo que genera esta relación de competencia entre los diferentes horizontes de igualdad posibles.

Buscar como horizonte de un proyecto de sociedad la igualdad en un aspecto de la vida implica al mismo tiempo promover o aceptar desigualdades en las restantes. Así, por ejemplo, buscar la igualdad en el pleno ejercicio de derechos de todos los ciudadanos puede significar la necesidad de promover desigualdades en los ingresos de sus familias, desigualdades que -en la medida en que nos acercan a ese horizonte deseado- pasan a ser justas. 
La noción de equidad remite precisamente a ello, al conjunto de desigualdades que se promueven para el logro de esa igualdad fundamental. No hay equidad sin igualdad, sin esa igualdad estructurante que define el horizonte de todas las acciones. La noción de equidad renuncia a la idea de que todos somos iguales, y es precisamente a partir de este reconocimiento de las diferencias que propone una estrategia para lograr esa igualdad fundamental. La igualdad es, entonces, una construcción social.

Desde esta perspectiva, la noción de equidad tiene un carácter eminentemente político. Por un lado, porque lleva implícita una valoración ética en su definición, al exigir una toma de posición sobre cuál es la igualdad estructurante que se define como horizonte. Por el otro, porque en tanto la equidad implica la búsqueda de la igualdad, esta igualdad fundamental que define los criterios de equidad no debe ser pensada como una situación dada, posible de ser mensurada en un momento específico, sino como un proyecto, un principio de organización que estructura el devenir de una sociedad.

Como bien señalan Fitoussi y Rosanvallón, "la equidad es la búsqueda de la igualdad a partir del reconocimiento de la diversidad". (FITOUSSI y ROSANVALLON, 1996) La igualdad es el horizonte, la equidad el camino. La igualdad el proyecto, la equidad la estrategia. No es posible pensar la equidad sin una noción de igualdad que la estructure, y no es posible pensar la igualdad sin la equidad como estrategia para hacerla viable.

\subsection{Equidad en educación}

Tomando en cuenta este modo de entender la equidad, la definición de un criterio de equidad en educación implica la necesidad de identificar una igualdad fundamental en torno a la cual estructurar un proyecto educativo. Marc Demeuse señala que existen al menos cuatro principios de equidad que compiten por imponerse en el campo educativo, organizados a partir de las siguientes igualdades fundamentales: igualdad en el acceso, igualdad en las condiciones o medios de aprendizaje, igualdad en los logros o resultados, e igualdad en la realización social de estos logros (DEMEUSE, 2004). Establecer un criterio de equidad en educación, y consecuentemente definir un horizonte de política educativa, implica entonces optar por una de estas igualdades fundamentales.

La agenda que actualmente estructura las políticas educativas en los países de América Latina se encuentra en un punto muy avanzado de una transición entre un principio de justicia que ponía el énfasis en la igualdad en el acceso -entendida como igualdad de oportunidades- hacia otro que toma como estructurante la igualdad en los logros o resultados. Históricamente hubo consenso en torno a la idea de que una política educativa era justa si garantizaba a todos los niños igualdad de oportunidades para ir a la escuela. Hoy, en cambio, el consenso está en que una política educativa es justa si a todos 
les garantiza igualdad en los aprendizajes. Este cambio adquiere relevancia al quedar plasmado en la mayoría de las leyes de educación sancionadas en las últimas décadas.

Ahora bien, de la noción de equidad antes desarrollada se desprende que para avanzar hacia esa igualdad en los logros en términos de aprendizajes se hace necesario promover un conjunto de desigualdades en los modos y los momentos en que cada uno debe ingresar al sistema educativo, y en el trato que recibirán a lo largo de su trayectoria escolar. Estas desigualdades, cabe insistir, se constituyen en desigualdades justas. Como ya se sabe, tratar a todos por igual en un contexto de grandes desigualdades es un modo de reproducir y consolidar esas desigualdades; del mismo modo, tratar a todos por igual en un contexto de gran diversidad implica instalar prácticas discriminatorias en el corazón de las instituciones educativas.

\section{DESIGUALDAD Y DIVERSIDAD}

Uno de los grandes desafíos que enfrentan las políticas educativas -y las políticas sociales en general- es lograr intervenciones efectivas en contextos en que todos somos distintos. En términos de los sujetos que las componen, nuestras sociedades son sumamente heterogéneas, y diariamente cada uno de nosotros está en una interacción permanente con otros cuyas identidades tienen pocos elementos en común con la nuestra. ¿Cómo dar cuenta de esa gran heterogeneidad social? ¿Qué categorías nos permiten describir las formas que adquiere ese "ser distintos"? Podemos sostener que somos distintos porque somos desiguales, del mismo modo que podemos afirmar que somos distintos porque somos diferentes. Desigualdad y diversidad se articulan, y es en esa articulación que confieren especial complejidad al escenario social.

Cuando se habla de desigualdad se remite a modos de ser distintos que son cuantificables, que se expresan en que unos tienen más que otros. Puede ser más ingresos, más propiedades, más educación, más experiencia. La diversidad, en cambio, hace referencia a diferencias que no son cuantificables, que no se pueden expresar en más o en menos. Son diferencias cualitativas. La diversidad se materializa -por ejemplo- en ser de nacionalidades diferentes, por el género, la etnia o las preferencias culturales. No es más ni es menos, sólo es diferente.

La desigualdad y la diversidad son dimensiones que si bien son posibles de diferenciar desde el punto de vista analítico, aparecen con un cierto grado de articulación en cada escenario social específico. Ciertos grupos identitarios -como por ejemplo los indígenas de América Central- se ven mayoritariamente expuestos a situaciones de pobreza. En contraste con ello, los migrantes que llegaron a la región provenientes de algunos de los países de Europa suelen pertenecer a las clases medias o altas. Esto es, en muchos casos 
aproximarse a ciertos grupos sociales por su identidad o pertenencia cultural es, al mismo tiempo, aproximarse a estratos específicos de la estructura social.

Hay dos razones por las que esta heterogeneidad de identidades y perfiles de los miembros de una sociedad -que se expresa en la articulación de desigualdad y diversidadse constituye en un desafío central para las políticas educativas. Por un lado, y desde un punto de vista operativo, porque instala la necesidad de desarrollar estrategias institucionales o pedagógicas que tomen en consideración esa compleja heterogeneidad. Toda política de equidad educativa implica, como ya se señaló, promover desigualdades justas orientadas a avanzar hacia el horizonte de igualdad en los logros de aprendizajes socialmente esperados. Ello implica generar acciones que sean sensibles a las formas específicas que adquiere en cada contexto la articulación de diversidad y desigualdad

Pero además -y esto es central en la definición de una política- porque en ese "ser distintos" operan diferentes factores que confieren a algunas personas más poder o mayor prestigio que a otras, lo cual coloca entre los fines de esas políticas operar precisamente sobre los efectos de esos factores diferenciadores. Nancy Fraser hizo significativos aportes que nos permiten comprender cómo la desigualdad y la diversidad se constituyen en barreras a los procesos sociales que se inscriben en la búsqueda de un horizonte de justicia. Por un lado, las personas pueden verse impedidas de una participación plena en los procesos sociales "por las estructuras económicas que les niegan los recursos que necesitan para interaccionar con los demás como pares" (FRASER, 2008:39). Aquí la desigualdad aparece en su expresión más clara, en tanto volúmenes distintos de las diferentes formas de capital se traducen en desiguales posibilidades de participación o de ejercicio del poder. Pero además -señala la misma autora- "las personas pueden verse también impedidas de interactuar en condiciones de paridad por jerarquías institucionalizadas del valor cultural que les niegan la posición adecuada" (FRASER, 2008:40). La valoración que se hace del ser masculino es distinta a la del ser femenino; en la realidad que hoy vivimos no es igual la vida para quienes son blancos y para los afrodescendientes. Se deposita en cada rasgo de identidad una valoración distinta, diferentes prestigios o status, que convierte a la diversidad en un factor de tensión, conflicto o discriminación. La articulación de la desigualdad y la diversidad como aspectos que configuran el escenario social en que se inscriben las prácticas educativas enfrenta a las políticas no sólo con el desafío de generar dinámicas acordes a las características de cada grupo social, sino que también deben sostener entre sus objetivos el compromiso de operar como políticas de redistribución orientadas a desactivar las barreras de clase- y de reconocimiento -neutralizando aquellas que se derivan de las asignaciones de estatus y prestigio-. (FRASER, 2008)

Diversidad y desigualdad son, entonces, dos categorías que si se las analiza por separado pierden potencia como herramientas analíticas. En un texto como éste, en el cual se está poniendo el foco en la diversidad cultural, no se renunciará entonces a hablar de la 
articulación que ésta tiene con la desigualdad. En todo caso, lejos de optar por una u otra categoría, el análisis realizado invita a enfatizar más en una de ellas, dejando abiertos los puntos de enlace o articulación con la otra.

\section{LA DIVERSIDAD EN LAS AULAS}

Hasta aquí el análisis se mantuvo en un plano más conceptual, buscando organizar ciertas categorías analíticas que permitieran comprender el desafío en términos de políticas educativas que se desprende de la irrupción de grupos muy heterogéneos de estudiantes en las aulas. Hablar de la diversidad en las aulas invita a una reflexión estructurada sobre una base empírica. En este caso, este texto toma a América Latina como espacio proveedor de imágenes de la realidad y apreciaciones desde donde avanzar en el análisis. En consecuencia, las referencias al panorama actual o las conclusiones a las que se llegue, aunque estén planteadas en términos generales, se consideran válidas sólo para esta región, no así para otras.

Cuando se analiza el panorama educativo de las últimas dos décadas en América Latina se aprecia que uno de los hechos más relevantes que se vivieron es la significativa expansión del nivel medio de educación. Este proceso viene de la mano de una profunda redefinición del rol de la escuela media ante la sociedad. Un nivel educativo que nació con un claro espíritu de selección de los adolescentes y jóvenes -encaminándolos hacia diferentes trayectorias laborales o profesionales futuras- recibe el mandato de sumarse a un proyecto de inclusión educativa y garantía de derechos. Este cambio en la identidad de la escuela media, como se verá más adelante, es un factor central para entender muchos de los mecanismos de discriminación actualmente vigentes en las instituciones educativas. De todos modos, de la mano de esa redefinición del nivel llegó un conjunto de acciones -ampliación de la oferta educativa, becas, eliminación de instancias formales de selección, etc.- que promovieron un significativo incremento en el ingreso y la permanencia de los adolescentes en el nivel medio ${ }^{1}$.

¿Quiénes fueron los grandes protagonistas de este proceso de inclusión en las escuelas medias? Aquellos grupos sociales para quienes el ingreso a ese nivel estuvo vedado. Desde ya, los estudiantes provenientes de los sectores más pobres. Pero además, irrumpieron en las escuelas indígenas, afrodescendientes, migrantes, u otros jóvenes con perfiles y rasgos de identidad que históricamente no tenían acceso a ellas. Así, la diversidad entró a las aulas, poblándolas de caras nuevas.

\footnotetext{
${ }^{1}$ Para un mayor conocimiento de la magnitud de este proceso de expansión de la educación media en la región se pueden consultar los documentos elaborados por el Sistema de Información de Tendencias Educativas en América Latina (SITEAL) en www.siteal.org
} 
Las fuentes de diversidad en América Latina son múltiples. Hay una diversidad estructural, que se remonta a las raíces culturales de la región. Coexisten en la región un gran número de pueblos originarios, con sus lenguas y tradiciones aún vigentes. A ellos se sumaron los europeos que participaron del proceso de colonización a partir del siglo XV en su mayoría españoles y portugueses- y de la mano de ellos, los africanos que fueron traídos como esclavos. Con la conformación de los Estados Nacionales, hacia fines del siglo XIX, llegaron a la región italianos, árabes, familias de Europa del Este u otras oleadas de migrantes que sumaron complejidad al mapa de identidades de la región. La globalización, como fenómeno más reciente, profundizó los procesos migratorios, permitiendo la llegada de familias provenientes de zonas hasta ahora poco visibles en el territorio, y acelerando los procesos de movilidad entre países limítrofes.

Pero la diversidad en las aulas va más allá del origen o la lengua que hablen los estudiantes. Cuando se trata de adolescentes o jóvenes, la variedad de referentes desde los cuales ellos van construyendo su identidad, y que los van congregando en torno a ciertos núcleos de pertenencia, pasa a ser también un rasgo de diversidad que impregna las aulas. En especial en los grandes centros urbanos, cada ciudad o metrópolis tiene su abanico de tribus o grupos de pertenencia de las nuevas generaciones, que llegan con sus estéticas y sus lenguajes a las aulas. Deberíamos sumar a este conjunto de factores de diversidad la identidad de género, cuando ya es cada vez más habitual que homosexuales o travestis asistan a las clases decididos a no ocultar su identidad.

De todos modos, en la medida en que se aborde el análisis de la diversidad desde una perspectiva de las culturas o espacios de pertenencia siempre estaremos remitiendo a grupos poblacionales específicos: los indígenas, la comunidad china en las grandes ciudades, los transexuales, los youtubers. El riesgo aquí es tender hacia una imagen de sociedad que se asemeja a un conjunto de mosaicos, algunos más grandes que otros, a un cuadriculado que alberga en cada celda un grupo homogéneo de personas. Aproximarse al tema de la diversidad implica más que eso. Es asumir que todos y cada uno de nosotros somos distintos. En parte por nuestro origen o grupo de pertenencia, pero también por el modo en que en nosotros se articulan las múltiples dimensiones de la vida que hacen a nuestra identidad.

El análisis de la diversidad implica entonces dos registros. Por un lado, uno más macrosocial, en el cual se pone el énfasis en la identificación de grandes grupos identitarios cuyos rasgos se fueron configurando en la historia, y apela al origen de las personas, los procesos migratorios que subyacen a sus historias de vida, o las elecciones que fueron realizando al momento de construir sus espacios de pertenencia. La mirada está puesta, en este caso, en colectivos, en grupos de personas. Pero además hay otro registro de análisis que invita a orientar la mirada a un nivel más micro, centrando la atención en el sujeto. En 
este caso, hablar de identidad es -como se señaló- entender a ese sujeto como único, con sus particularidades, sus modos de ser, sus elecciones y sus expectativas.

\section{LA INCLUSIÓN EDUCATIVA}

La escuela media -tal como ya se señaló- está en pleno proceso de transformación. Se encuentra en el tránsito de ser una institución cuyas prácticas se estructuraban en torno a la misión de selección y clasificación de las nuevas generaciones hacia otra que debe sumarse al proyecto de inclusión educativa que impera -al menos en un plano declarativohoy en la región.

La idea de educación inclusiva atraviesa el debate sobre las políticas educativas en América Latina. En la medida en que los marcos normativos de cada uno de los países van destacando que la educación es un derecho humano fundamental y un bien público, y que es responsabilidad de cada uno de los Estados consolidarse como garante de ese derecho, la noción de inclusión se convierte en uno de los horizontes de la agenda regional. Adquiere relevancia a partir de la declaración internacional de los derechos del hombre, pero es recién a mediados de la década de los años 80 que comienza a tomar forma a través de acciones o programas específicos, fuertemente asociados la incorporación de alumnos caracterizados como con necesidades especiales a las escuelas comunes. Paulatinamente se fue ampliando el universo de situaciones a las que fue abarcando este tipo de acciones, pero siempre tomando como criterio diferentes formas de vulnerabilidad. Hoy el debate busca trascender esta visión, y apunta al fortalecimiento de las capacidades institucionales para hacer efectivo el horizonte de una educación para todos desde una perspectiva universal. "La educación inclusiva implica primariamente y ante todo la apertura, la voluntad y las competencias para respetar, entender, aceptar y apoyar la diversidad de perfiles, circunstancias, expectativas, necesidades y estilos de los estudiantes como fuente para democratizar y mejorar las oportunidades, los procesos y los resultados de los aprendizajes y de la adquisición de competencias ciudadanas y de vida" (ACEDO y OPERTTI, 2012).

La noción de inclusión se va consolidando en torno a la de no discriminación. Un punto central de la estrategia es, precisamente, la plena vigencia del principio de no discriminación en las instituciones escolares. Ello implica una actitud de reconocimiento de cada sujeto, independientemente de su lugar en la estructura social o en el espectro de identidades o pertenencia cultural. Una educación inclusiva apuntaría -desde esta perspectiva- a la construcción de un vínculo entre el docente y cada uno de sus estudiantes basado en el pleno reconocimiento y el respeto mutuo. 


\subsection{Las barreras a la inclusión}

Los hechos demuestran que si bien hubo -como ya se señaló- significativos avances en los procesos de inclusión educativa, es mucho lo que queda por hacer para garantizar el pleno ejercicio del derecho a la educación entre los adolescentes. ¿Cuáles son los factores que están detrás de los procesos de desescolarización que se dan en las escuelas del nivel medio? Desigualdad y diversidad se articulan para configurar un escenario sumamente complejo en el cual la función estatal de garantía del derecho a la educación aún no logra consolidarse en la región. Las desigualdades económicas atentan contra la posibilidad de universalizar el acceso al conocimiento. Para cada niño ingresar a la escuela en su primera infancia, permanecer escolarizado hasta el final de su adolescencia y hacer un aprovechamiento adecuado de esa experiencia que le permita lograr aprendizajes significativos e integrales significa un esfuerzo muy importante, difícil de sostener en contextos de pobreza. La escolarización requiere tiempo, salud, espacio, energía y motivación, factores que difícilmente puedan sostenerse en contextos de escasez de recursos. Uno de los factores principales de desescolarización de los adolescentes en la región es la dificultad de mantenerse desvinculados de las dinámicas familiares de construcción de bienestar. Sea porque deben salir de modo temprano a trabajar y aportar ingresos al hogar (más habitual entre los adolescentes varones) o porque quedan entrampados en dinámicas familiares orientadas a la producción de cuidado de aquellos que lo requieren en el hogar (en general las mujeres), para una familia de bajos recursos la educación de sus hijos es un proyecto no siempre viable (D'ALESSANDRE, 2014).

Pero no sólo la desigualdad opera como barrera a la universalización del acceso al conocimiento, como obstáculo a una educación para todos. La persistencia de diferentes formas de discriminación en las instituciones educativas hace que la diversidad de perfiles identitarios y culturales en el alumnado se constituya también en una barrera al proyecto de inclusión educativa. La aparición de estudiantes de distintos orígenes sociales y culturales en las aulas representa para las instituciones un gran desafío en términos operativos, pues exige que las dinámicas escolares o los modos de dar clases no puedan ser iguales en todos los contextos. Los estudiantes hoy traen diversos idiomas, diferentes grados de integración a las culturas locales y como parte de ello distintos modos de interactuar con la autoridad o en marcos institucionales específicos, todos aspectos que exigen una revisión de cada uno de los detalles de la propuesta educativa que se elabora, y una revisión constante del grado de pertinencia que tiene en cada situación repetir los formatos y las dinámicas históricamente instituidas.

Pero además de este desafío que se inscribe en un debate didáctico, pedagógico y curricular, la inclusión de nuevos perfiles a las aulas pone en evidencia la necesidad de un esfuerzo ético y valorativo. En conversaciones con docentes y directivos suelen aparecer referencias que ponen en atributos específicos de los alumnos las razones de sus fracasos: 
“¿cómo le va a ir bien en la escuela si su padre está preso?” “¿qué espera de este chico si su madre cambia de marido cada año?” El análisis de los mecanismos de discriminación y selección que tienen su soporte en la diversidad de los alumnos requiere centrar la atención, por un momento, en los diferentes actores e instituciones del sistema educativo.

\section{$\underline{5.2 \text { Actores e instituciones }}$}

Las dinámicas institucionales se materializan en el accionar de sus agentes. Son ellos, los directivos, los maestros o el personal de apoyo, quienes día a día expresan en sus actos a las instituciones escolares que enmarcan su función. Lo que ellos hacen les da vida a las instituciones, pero al mismo tiempo habla de ellas.

\subsubsection{Los agentes educativos}

El accionar de los docentes pone en evidencia la persistencia de prácticas que denuncian un desajuste entre el modelo de alumno que la escuela espera y el alumno que realmente ingresa a ellas. En trabajos anteriores hacía referencia a esta tensión diferenciando entre el "alumno ideal" y el "alumno real". La noción de alumno ideal no remite en este caso al alumno que se quisiera tener, aquel deseado, sino al alumno genérico, expresado en una abstracción, para el cual la institución se prepara, para el cual diseña su dinámica. ¿En qué alumno piensa cada docente cuando planifica sus clases? ¿Qué recursos imagina que ese alumno trae al aula, para poner en acción en su interacción con él? En el marco de los estudios que he realizado desde el IIPE se fue acumulando evidencia que invita a concluir que cada vez más los alumnos que ingresan a las aulas poco tienen que ver con aquel para el cual son diseñadas las prácticas escolares. (LÓPEZ, 2005)

El diálogo con los docentes, en entrevistas realizadas, pone en evidencia este desajuste. Suelen explicar las dificultades de aprendizaje o el fracaso de ciertos alumnos poniendo el énfasis en algunas características de ellos, pero lo interesante es que esas características son definidas por la negativa: no los caracteriza lo que son o lo que tienen, sino aquello que les falta. Así, por ejemplo, suele decirse que a un estudiante le va mal en su trayectoria escolar por no tener tiempo para estudiar, por no tener una familia que lo apoye, o por no participar en las clases. De ese tipo de enunciados sería posible concluir que sus clases fueron planificadas para estudiantes que cuentan con tiempo extra, el apoyo de las familias y que son participativos. Es de este modo que Stigaard concluye -analizando entrevistas realizadas en Argentina, Chile, Colombia y Perú- que el alumno que los agentes educativos esperan es aquel que sabe hacer su trabajo como estudiante, es autónomo en responder a sus aprendizajes, realiza sus trabajos, lee bastante, sabe proyectarse hacia el futuro, no necesita que nadie le diga qué debe hacer, es consciente del papel que tiene como estudiante y como ser social, tiene interés en mejorar, en superarse, es solidario, democrático, resolutivo, emprendedor, puntual, cuenta con el apoyo de su familia, es 
comprometido, activo, partícipe, disciplinado, aplicado y respetuoso (STIGAARD, 2012). ¿Hay alumnos así?

Frente a ese desajuste entre el alumno ideal -ahora así, aquel deseado por los docentes- y los alumnos que hoy entran a las aulas las respuestas de los agentes educativos son múltiples. En muchos casos se instala un sentimiento de frustración e impotencia. La sensación de que nada se puede hacer en este contexto, la puesta en duda de si tienen sentido los esfuerzos. Son muchos los docentes invadidos por esta frustración, fuente de un malestar con el ejercicio de su tarea, de desestímulo y parálisis. En otros casos, la constatación de que no se está logrando que los estudiantes aprendan, o en muchos casos la irrupción de un caso crítico, lleva a la búsqueda de respuestas innovadoras y colectivas. Por iniciativa propia, y habitualmente fuera de todo encuadre institucional, docentes y directivos se juntan a pensar soluciones y comienzan a experimentar nuevas salidas. Muchas de las experiencias exitosas que hoy se analizan en términos de propuestas institucionales innovadoras nacieron de este modo, en reuniones fuera del horario de clases, seguramente en casa de alguno de los docentes, reunidos por la angustia que les producía este nuevo desafío. En otros casos, el malestar se convierte en enojo. Enojo con la comunidad, enojo con los estudiantes, que se va transformando en descalificación y desprecio. No son pocos los casos en que se percibe una actitud muy violenta en el modo en que los docentes y directivos hablan de sus estudiantes, comentarios a los que subyace una valoración negativa de ciertos grupos, y la certeza de que la escuela no es para ellos. Escalas de prestigio o estatus que operan como sustento para expresar que la escuela es para unos, pero no para otros (LÓPEZ, 2011).

En los tres casos se percibe un factor común: la angustia que genera la dificultad de encarar día a día este nuevo escenario. Y las tres salidas a esa angustia -la parálisis, la acción o el desprecio- nos hablan de la ausencia de recursos con la que estos agentes educativos están afrontando su tarea cotidiana. Por un lado, ausencia de formación; en términos generales, los docentes no están bien preparados para abordar este desafío, no tienen los recursos necesarios para desarrollar estrategias adecuadas a cada grupo de estudiantes, no recibieron un entrenamiento que les permita encarar con confianza cursos heterogéneos y perfiles nuevos en las aulas. Por el otro, ausencia de un marco institucional y normativo acorde al desafío planteado. Puede percibirse en las entrevistas que es habitual que los docentes no tengan a quién recurrir para recibir apoyo ante situaciones concretas, que no haya mecanismos claros de resolución de conflictos, faltan protocolos o criterios consensuados para la toma de decisiones, o un trabajo de equipo pautado con los diferentes colegas de cada institución. Las referencias a la soledad son recurrentes en el discurso de los docentes. Aún en el caso en que se encuentran salidas exitosas para este desafío, éstas suelen nacer desde iniciativas personales carentes de un marco institucional o normativo. 
¿Qué es lo que constituye a cada docente en un agente público, en parte del entramado estatal de garantía de derechos? Son precisamente una formación específica, acreditada, y un marco normativo e institucional. La ausencia de estos recursos despoja a cada sujeto de su investidura de agente. Frente al aula ya no hay un agente, sino un sujeto carente de esos recursos, una persona teniendo que asumir una tarea que no puede. Y esa persona recurre a lo que tiene: el recuerdo de cómo la educaron a ella, lo que intuye que está bien, su buena voluntad y su entusiasmo, o tal vez su falta de estímulo y sus prejuicios. ¿Puede un docente ser docente sin un marco institucional adecuado?

\subsubsection{Las instituciones}

Las instituciones escolares se constituyen así en un foco sumamente relevante de análisis. La dificultad de avanzar en el proceso de expansión y universalización de la educación remite a diferentes ejes de debate, y uno central es pensar la institución educativa hoy. Subyace a esta preocupación cierto consenso de que la escuela media, tal como es hoy, no responde a las expectativas que sobre ella se depositan.

Cabe pensar aquí en dos hipótesis desde las cuales intentar comprender esta debilidad o crisis de la institución escolar. Una de ellas pone el énfasis en la idea de deterioro. La otra, en cambio, en la inercia. América Latina vivió, durante la década de los años 90, un conjunto de transformaciones políticas e institucionales muy profundas enmarcadas en la implementación de los lineamientos del pensamiento neoliberal. Estas reformas tenían como horizonte priorizar a los mercados como elemento dinamizador y estructurante de las sociedades, limitando la función social del Estado a dar respuesta a las necesidades de las familias pobres, aquellas que quedan precisamente fuera de esos mercados. Dinámicas de mercado y políticas focalizadas son elementos centrales de ese modelo. Bustelo destaca que la noción de focalización no sólo es orientar recursos públicos hacia los sectores más pobres, sino también reducir el flujo de estos recursos hacia los sectores medios, desestimulado así el uso de la oferta pública y promoviendo su corrimiento hacia el mercado. Esto se tradujo en un proceso de desfinanciación de la escuela pública, y un profundo deterioro en términos de infraestructura y salarios (BUSTELO, 2000). El proceso de expansión de la escuela media -caracterizado por la necesidad de ampliar la oferta educativa- se dio en la región en este marco. Es esta misma escuela que venía de más de una década de políticas que la fueron debilitando la que debe generar respuestas a la ampliación de la demanda, y a la incorporación de estas caras nuevas en sus aulas. Una institución que viene de un proceso de profundo deterioro es la que tiene que asumir uno de los desafíos más complejos que enfrentan los sistemas educativos en la actualidad.

Por otra parte, cabe recordar que -como ya se señaló- la escuela media tiene en su origen el mandato de seleccionar y orientar a los jóvenes hacia diferentes circuitos en el 
mundo productivo. Recursos como la selección al ingreso mediante exámenes de admisión y la posibilidad de expulsar a aquellos alumnos que no cumplen con la expectativa institucional, o la creación de circuitos diferenciados orientados a ofrecer diferentes perfiles de formación para distintas categorías o tipos de tareas en el mundo laboral fueron elementos centrales de la identidad de este nivel. A esa institución se le pide hoy que se sume al proyecto de inclusión educativa y garantía del derecho a la educación. La segunda hipótesis apuntaría, en este marco, a señalar una escuela que no cambia, que permanece estable, inmutable, insensible a las transformaciones que se van dando fuera de ellas, en la sociedad, o en sus aulas, escenario que en textos anteriores he caracterizado como "cambio social e inercia institucional" (LÓPEZ, 2005). El cambio social se produce, como se señaló previamente, en al menos dos niveles de análisis. Por un lado, contextos educativos más heterogéneos; por el otro, la demanda de una educación universal, y la consolidación de esa educación como un derecho humano fundamental. Frente a estos cambios de contexto y de demandas o expectativas sociales, la escuela se ve amenazada; la necesidad de redefinir su identidad y función social y de lograr un ajuste al nuevo escenario preanuncia la crisis de la escuela media. Frente a esta amenaza las instituciones educativas -lejos de abordar el cambio que se les exige- se resguardaban en su identidad histórica, la profundizaban. Así, ante la dificultad de sostener dinámicas gobernables que se traduzcan en algún grado de equilibro de la institución se decide en muchos casos privilegiar a ciertos grupos sociales por otros como estudiantes deseados en las aulas, planificar dinámicas escolares que sólo pueden ser aprovechadas y sostenidas por esos grupos, o mantener vivos mecanismos de selección y discriminación, ahora vigentes en forma encubierta. Una identidad institucional que se resiste a cambiar, rasgos inscriptos en una especie de ADN de la escuela que operan como anticuerpos a esas amenazas a las que el medio las expone.

Ambas hipótesis, la del debilitamiento desde el cual la escuela debe afrontar el cambio o aquella que pone el foco en la inercia institucional, no necesariamente compiten entre ellas. Por el contrario, pueden ser vistas como puertas de entrada a dos líneas de análisis que juntas ofrecen un mayor entendimiento de las dificultades que representa avanzar hacia los cambios que el nuevo escenario exige. Lo cierto es que ambos mecanismos dejan a los docentes solos con el desafío de establecer un diálogo productivo con esos múltiples alumnos, voceros y caras de la diversidad propia de las sociedades latinoamericanas.

\subsubsection{EI Estado}

De todos modos, el análisis de la institución escolar queda incompleto si no se la piensa como una institución del Estado, o cuyas prácticas están definidas y reglamentadas por éste. ¿En qué medida los Estados de la región promueven en sus instituciones dinámicas basadas en principios de no discriminación, y de reconocimiento de la identidad de los ciudadanos? Hay dos líneas argumentales desde las cuales sostener que los Estados 
tienden a promover prácticas que -lejos de basarse en el reconocimiento de la identidad de los ciudadanos- se sustentan en la negación de esas identidades.

Una de estas líneas remite a la historia de los Estados Nacionales en América Latina, y más específicamente a su origen, durante la segunda mitad del siglo XIX. En territorios poblados por criollos, indígenas, afrodescendientes o migrantes de diferentes regiones del planeta era necesario, como parte del proyecto de construcción de cada Nación, formar sus ciudadanos. La escuela fue la principal institución abocada a esta tarea, y la estrategia adoptada por ella fue igualar el trato hacia todos sus alumnos. El principio subyacente a esta estrategia era que tratando a cada uno de ellos como el ciudadano deseado, se terminarían convirtiendo en él. Tratando a indígenas y criollos como ese mexicano imaginado, ellos serían ciudadanos mexicanos. Los migrantes recién llegados de España e Italia al margen oeste del Río de la Plata serían convertidos en argentinos en la medida en que las instituciones estatales los trataran como ese argentino soñado por los fundadores de la nación. La estrategia de construcción del nuevo ciudadano de las naciones que comenzaban a nacer era precisamente negarles su identidad. El trato hacia quienes habitaban el territorio no se basaba en quiénes realmente eran, sino en la imagen que se tenía de quienes debían ser. La negación de la identidad de los sujetos está en el origen de las instituciones estatales, y en particular en el origen de la escuela. Su función primordial en ese momento no era reforzar identidades preexistentes, sino por el contrario construir una nueva.

Una segunda línea argumental centra el foco en el tipo de relación que el Estado, a través de sus instituciones, establece con los adolescentes y los jóvenes. Los análisis que centran la atención en ese punto tienden a destacar el carácter adultocéntrico de ese vínculo. Cuando se habla del adultocentrismo del Estado suele hacerse referencia a que las instituciones estatales están creadas por adultos, dirigidas y gestionadas por adultos y toman al adulto como único interlocutor válido. Desde esta perspectiva, suele denunciarse la incapacidad de las instituciones de establecer un diálogo con quienes no son adultos, basado en el respeto y el reconocimiento. En el ámbito educativo ello se reflejaría en el caso de las instituciones a las que asisten adolescentes y jóvenes, pues en las escuelas de los niños el interlocutor legítimo son sus padres.

Sin embargo, hay otro modo de entender el carácter adultocéntrico de los Estados. Éstos lo son en la medida en que sus prácticas se estructuran a partir del principio de que la adultez es el momento privilegiado de la vida de las personas (CHAVES, 2005). Desde esta perspectiva, un niño, adolescente o joven no es más que un adulto en construcción, una materia prima aún maleable. El rol del Estado es -entonces- modelarlo, encauzarlo, llevarlo hacia ese adulto deseado. Nuevamente, no importa quién es hoy, sino quién se desea que sea. No importa la identidad presente, sino aquella que se le quiere dar. Cabe pensar que 
difícilmente se pueda avanzar hacia un proyecto de inclusión social y educativa plena si no se pone en discusión el Estado que tenemos.

\section{CONCLUSIONES}

El panorama que se presenta es, sin dudas, complejo. Por un lado, las sociedades latinoamericanas se caracterizan por su extrema y creciente heterogeneidad. En el marco de profundas desigualdades -las más pronunciadas del planeta- los procesos de diversificación identitaria y cultural se van ampliando. Convergen allí una mayor capacidad de circulación de las personas en el territorio, las posibilidades que dan las nuevas tecnologías de interactuar con grupos de pertenencia que exceden a los alcances de lo local y adscribir a ellos, y al mismo tiempo la posibilidad creciente que tiene cada uno de mostrarse tal como es, en un clima de mayor aceptación de la diversidad. Por el otro, y de la mano de esos procesos, la demanda de una educación de calidad para todos en la que prime como central el principio de no discriminación, y de un Estado garante del derecho a la educación.

Los desafíos que quedan por delante son diversos. Desde el punto de vista analítico, son muchas las preguntas que queda por hacerle a esta realidad, para desentrañar las dinámicas concretas que van obstaculizando la meta de una educación de calidad para todos. Hay una voluntad creciente de consolidar a la educación como un derecho humano fundamental, de iniciar un proceso de transformación de cada Estado como garante de ese derecho y de promover una cultura del reconocimiento que valore cada momento del ciclo vital -especialmente a la niñez y la adolescencia-. Esa voluntad instala un nuevo abanico de temas en la agenda pública, y en consecuencia de problemáticas que aún han sido muy poco exploradas en el ámbito académico. Cada nuevo tema en la agenda pública implica nuevas preguntas desde las cuales organizar un diagnóstico, y nos confronta con la necesidad de apelar a nuevas categorías analíticas para poder responderlas.

Desde un punto de vista político, es fundamental tener presente que detrás de esos aparentes acuerdos que moldean la agenda actual hay grandes tensiones. No todos los sectores de la sociedad creen que la educación es un derecho de todos, y muchos ven amenazados sus privilegios si se habla de avanzar hacia sociedades donde la redistribución y el reconocimiento sean principios de justicia fundantes.

Esto implica que avanzar hacia un horizonte de igualdad en los logros educativos tiene una dimensión técnica operativa -en la cual identificar diferentes propuestas educativas para cada contexto social y cultural es uno de los ejes centrales- pero también tiene un claro e ineludible componente político. Hay que desarrollar estrategias de participación y de movilización que mantengan vivos los principios que subyacen a la agenda de derechos humanos, y al mismo tiempo abrir un fuerte debate sobre qué Estado es el que se necesita para que se apropie de esa agenda y la haga efectiva. 


\section{REFERENCIAS BIBLIOGRÁFICAS}

ACEDO, C. Y OPERTTI, R. (2012): Educación Inclusiva: de focalizar grupos y escuelas a lograr una educación de calidad como el corazón de una Educación para Todos (EPT)

RAMBLA, Xavier (editor). La Educación para Todos de América Latina: estudios sobre las desigualdades y la agenda política en educación. (Barcelona, Colección: Educación, Globalización y Desarrollo).

BUSTELO, E. (2000): De otra manera. Ensayos sobre Política Social y Equidad. (Santa Fe, Homo Sapiens ediciones).

CHAVES, M. (2005) Juventud negada y negativizada: Representaciones y formaciones discursivas vigentes en la Argentina contemporánea, en Última Década n²3, CIDPA VALPARAÍSO, DICIEMBRE 2005, pp. 9-32.

D'ALESSANDRE, V. (2014) El desafío de universalizar el nivel medio trayectorias escolares y curso de vida de los adolescentes y jóvenes latinoamericanos. (SITEAL, IIPE UNESCO Buenos Aires). Extraído de http://www.siteal.iipeoei.org/libro_digital/516/el-desafio-de-universalizar-el-nivel-medio-trayectoriasescolares-y-curso-de-vida-

DEMEUSTE, M. BAYE, A. STRAETEN, M y NICAISE, J (2004): A equidade dos sistemas educativos Europeus. Síntese a propósito da construçao de um conjunto de indicadores de equidade. Revista de Estudos Curriculares 2 (2), pp. 217-237.

FRASER, N. (2008): Escalas de justicia (Barcelona, Herder Editorial)

FITOUSSI J. Y ROSANVALLON, P (1996): La era de las desigualdades. (Buenos Aires, Ed. Manantial)

LOPEZ, N. (2005): Equidad educativa y desigualdad social. Desafíos de la educación en el nuevo escenario latinoamericano. (Buenos Aires, IIPE UNESCO)

LÓPEZ, N. (2011): "El desprecio por ese alumno" en N. López (coord.): Escuela, identidad y discriminación, (Buenos Aires: IIPE/UNESCO), pp. 235-256.

SEN, A. (1995): Nuevo examen de la desigualdad. (Madrid, Alianza editorial)

STIGAARD, M (2012): El Estado y la inclusión educativa de los jóvenes frente a la injusticia distributiva y cultural”, en N. López (coord.): Equidad educativa y diversidad cultural en América Latina. (Buenos Aires, IIPE/UNESCO).

\section{PROFESIOGRAFÍA}

\section{Néstor López}

Sociólogo graduado en la Universidad de Buenos Aires. Se desempeña actualmente como coordinador de estudios de educación y equidad de la sede regional de IIPE - 
UNESCO en Buenos Aires, y es, además, coordinador del Sistema de Información de Tendencias Educativas de América Latina (SITEAL), una iniciativa de IIPE - UNESCO con la Organización de Estados Iberoamericanos. Previamente tuvo a su cargo el programa de estudios e investigaciones de la oficina de UNICEF en Argentina. Docente en la Maestría en Diseño y Gestión de Políticas y Programas Sociales de la sede de FLACSO en Argentina, y en la Maestría en Políticas Sociales de la Universidad de Buenos Aires, tiene publicados diversos trabajos que estudian cuestiones relativas al análisis de la estructura social, la pobreza, el mercado de trabajo y la educación. Datos de contacto: Agüero 2071, CABA, Argentina (1425). Teléfono: +5411 48069366. Email: n.lopez@iipebuenosaires.org.ar

Fecha de recepción: 14 de julio de 2015.

Fecha de aceptación: 11 de marzo de 2016. 